\title{
Optimal approaches to pregnant women with COVID-19
}

\begin{abstract}
The global COVID pandemic results in numerous tragic outcomes. One, though hopefully not common, is newborns being born and even dying. This piece highlights ethical dilemmas and clinical practices that may be optimal for these mothers and these infants before and after mothers deliver. The interventions discussed include reducing fetuses' risks during birth, bonding, and mothers and parents maximizing the meaning they derive from whatever happens, even when their child dies. Finally, when and whether these mothers should participate in research is discussed. The goal throughout is to identify ways in which the tragic outcomes to which these fetuses, mothers, and parents can be reduced, to the degree that this is possible.
\end{abstract}

Keywods: pregnant women, fetus, bonding, preterm labor, interventions
Volume 6 Issue 4 - 2020

\author{
Edmund G Howe \\ Programs in Ethics, Uniformed Services University of the Health \\ Sciences, USA
}

Correspondence: Edmund G Howe, Director, Programs in Ethics, School of Medicine, USUHS, USA,

Emailedmund.howe@usuhs.edu

Received: July 09, 2020 | Published: July 24, 2020

\section{Introduction}

There are relative few studies at this time concerning the effects of COVID-19 on pregnant women and their neonates. Since this pandemic has just recently come upon us, we know little regarding the effects of this virus and the different therapies we might use to combat it, particularly during these mothers' first and second semesters. Fortunately, it appears that COVID does not cause the profound vertical transmission HIV did. (1) Still, COVID and infections in mothers it causes may pose serious problems. COVID may, for example, cause preterm labor, fetal distress and even perinatal death. ${ }^{1}$ The worst outcome for these mothers and fathers and other mothers' partners is, of course, when these children die, uncommon though this may be. The pain for these people may be still worse if it is possible that this virus may have been a factor. This is because they may then feel guilty. ${ }^{2}$ Many people have a propensity to see themselves as having been at fault when this is at all plausible. Thus, mothers who believe they may have contributed to their having this virus may feel doubly vulnerable in this way. Anticipating the agony these prospective parents may feel suggests the potential importance of providers considering this in advance even when their children may be the rare ones that die. This pieces will consider these approaches with an emphasis upon the ethical questions that may arise. I shall do this in three major sections. In the first, I shall review policies that may be determined in advance, I shall then review practical interventions that providers may carry out. I finally shall discuss these mothers' participation in research.

\section{Policies}

This section will discuss three policies. The first involves mothers with COVID who want to deliver at home. The second involves selected issues related primarily to mother and fetus bonding. The third involves potential conflicts between mothers' and their fetus's medical interest and the more general question how dilemmas such as this should be best decided.

\section{Delivering at home with a mid-wife}

An ethical question and conflict that has arisen is the conditions under which providers should attend home births. This question may arise, too, when mothers have COVID. The main conflict posed when this conflict occurs likely would be between bringing about the best outcomes for both the mother and her fetus versus respecting these mothers' autonomy by accepting a possibly greater risk of a suboptimal outcome to follow to a greater extent what these mothers most want. They may want, for example, not only to be delivered by a midwife at their home, but, in addition, request that a pediatrician there join them if they have reason to believe that their fetus may be at some increased risk. This request is further complicated, of course, because even though the pediatrician has special knowledge and equipment, she, he, or they may need may be available only at a hospital.

How then these providers should respond when mothers make this request has been debated and if mothers with COVID make this request, there are additional issues that then will be at stake. These will involve, for example, their relative risks and protections from others. One group considering this offered the following two "take-home" conclusions: "First, the perinatal outcomes of planned home birth are worse than those of planned hospital births in countries such as the United States, which does not have integrated obstetric services and which permits a wide variety of midwifery training and certification; and, second, "the risk of infection from planned home birth is likely higher than that from planned hospital birth."

\section{Issues related to bonding}

The gains to both mothers and children from their having the opportunity to bond as from skin-to-skin contact are wellacknowledged. These may include even special benefits to neurodevelopmentally disadvantaged infants, for example, due, perhaps to biological effects of oxytocin. ${ }^{4}$ How this bonding should and should not occur may be complicated again by the COVID virus. The paradigmatic example of this may be that posed above of skin-to-skin contact. Providers may have different views regarding how and when this should occur. The length of time that has elapsed since the mother first was found to have this virus may be here, for instance, a critical medical factor. Although the ideal setting for a healthy infant is within a healthy mother's room, temporary separation of an ill mother and her infant, as was recommended during the previous H1N1 pandemic, may seem, too, now most prudent. ${ }^{5}$ Here, too, mothers' preference may play a role and ethically, their autonomy. This is an instance in which their strong wants may warrant some moral weight, even if 
and though providers following them may allow at least a greater theoretical risk. This outcome may differ, then, from what providers may more conservatively advise.

Another example related to this initial issue of bonding is with fathers. Here again, this opportunity may be most beneficial to both. Should, though, fathers have skin-to-skin contact? Again COVID presents new and additional problems. Concern has been raised that people other than these babies' mothers holding them, even with masks, may pose greater risks. Since the risk of transmission may be increased, providers, again, possibly being more conservative, have in some instances advised against this. Breast-feeding as a third example may not need to be contraindicated, at least since it now appears that this virus is not likely to be passed on in mothers' milk. There have been, however, concerns regarding this close contact during breastfeeding identical to those noted above. It is feared, for example, that breast-feeding might risk droplet or contact transmission from the mother to her child. There is, it would seem, general agreement that breastfeeding can be instituted after mothers are no longer infectious. Data are now, however, not deemed sufficient to give definitive guidance as to the "length of separation" that would be optimal. Thus, it is now recommended that this be decided on a case-by-case basis after discussion between infection control experts. (5, at 424) This allows, of course, this source of disagreement, once again.

\section{ECMO and other medical procedures which may pose a conflict between these mothers' and their fetuses' best interests}

These mothers may become most seriously ill. Then, they may need extracorporeal membrane oxygenation (ECMO) support. This may be life-saving. If and when this need now arises, it is recommended that ECMO only be considered in centers that have experience with this technique..$^{5}$ It may be in these instances, however, that what is best for these mothers may differ from what is best for the fetuses they are carrying. The effect of venous-arterial (VA)-ECMO on uterine circulation is, for example, not known. If this form of support is required in a viable pregnancy, therefore, currently, continuous fetal monitoring is recommended. ${ }^{6}$ Somewhat ethically analogous concerns arise as well in other ways. Whether delivery provides benefit to a critically ill mother is, for example, unknown. (5, at 424) Decisions regarding delivery should now, therefore, it is thought, consider the gestational age of the fetus and be made in conjunction with a neonatologist. ${ }^{5}$

\section{Who should decide? and how?}

Though the above conflicts have arisen before in other contexts, COVID alters what may be their chief concerns and even outcomes. This virus has been isolated, for example, from feces. This means that it is possible that vaginal delivery poses a greater risk for infection of the infant. ${ }^{1}$ We might ask here, finally, in regard to all these conflicts regarding policy like those above, how these might be best decided. One approach that has been urged is for providers of different specialties to meet regularly, daily, to decide what approaches they would favor and then share the conclusions they have arrived at with these mothers. This approach, however, risks minimizing to too great an extent the input mothers could give expressing their personal preferences. In risking this, this may go, too, too much against the current emphasis and ethical preference toward using a "shared decision-making" approach which involves all parties sharing input to a greater extent. ${ }^{7}$ A specific example involves the question who should decide when patients should discontinue ECMO. Depending on its intended use, this decision may determine these patients' death. Some providers assert that they should be the ones to make this decision, as they should be when they decide to discontinue efforts at cardiopulmonary-resuscitation. Some have, however, disagreed. ${ }^{8}$ They have felt that if not these patients, their surrogate decision-makers should have a place here. With COVID, this question too may have a place.

Though, too, some may regard shared decision-making as the edge of this field, as we shall see shortly in the next section this may not at all be the case. That is, we shall see there what may be some clear examples in which providers, as opposed to remaining more-or-less neutral in regard to what mothers and prospective parents should do, should strongly and even repeatedly urge them to take certain actions, though these parties may initially much oppose them. This approach, as we shall see, presupposes that providers may have knowledge and insight that patients and parents sometimes lack. Then the higher and highest clinical and moral roads may be for providers to do all they can to impart to these people what they know and then these others may most likely be glad that they have so urged this. ${ }^{9}$

\section{Practices}

In this section, I shall focus on possible optimal interventions for mothers and their partners when their infants have died. These practices alone make no more than a small beneficial difference. Given together, however, the difference they make may be most remarkable. They may change these parents' outlook, for example, from overwhelming grief that continues, to their wanting to risk having other children in their future. ${ }^{8}$ As to whether providers should later urge this, some have proposed, logically enough, that the "best advice" seems to be that the mother should wait until she, herself, feels ready. ${ }^{10,11}$

\section{Parents may savor every living moment}

It has not been uncommon in the past some have reported that providers have advised mothers whose fetuses have conditions from which they will shortly die to have abortions. Likewise, they have encouraged parents whose newborns are dying to stop life-prolonging treatment early on. Both practices may have been more harmful than beneficial. This is because we now know more that parents may cherish having more time with their infants even when they are stillborn and even if they soon will die. They may, in fact, want to hold and cherish them as long as they can. ${ }^{12}$ Providers, therefore, should take initiative to at least inform these parents that this may be the case. Likewise, as we shall review in more detail shortly, they should also inform them and perhaps also go further to urge them to also take other steps that may be similarly, to some providers, counter-intuitive. We shall now look at some key steps they should take in more detail.

\section{Seeing, holding, and bathing}

Parents may be reluctant to see and hold their babies after they have died. This may be for many reasons. ${ }^{13}$ Providers should, of course, not only inquire in order to recognize these reasons but then should go on to validate them by indicating that they understand them. At this same time, however, they should not encourage closure on this question. ${ }^{14}$ Rather, they should inform these parents that if, while they still can, but fail to see, hold, or even bathe these infants, this may be a choice that later they may dearly and deeply regret. ${ }^{15}$ They should indicate that this in fact has been the experience of many and they might add, all too many parents. ${ }^{16}$ Due to the ambivalence about doing this that these parents may feel and express, providers, most understandably, may not want to do this. This involves their going beyond being just neutral and respecting these parents' views. This response may be optimal, because as this example well illustrates, parents may not 
know or even consider doing this unless their providers, knowing this, tell them.

For these same reasons, some providers take what they see as their duty here further and believe that they should then ask parents who have not taken this route whether they might want to repeatedly. These parents' views and feelings may, they assert, have changed. I would add to this that if providers have this perspective, they initially should state that they would want to do this and give their reasons. They then should ask these parents if their continuing to ask them if they have changed their mind would be okay with them.

\section{The importance of retaining ways to remember}

Likewise, parents retaining ways to remember may be an endeavor too painful initially for parents to pursue. Yet, it may be and is, in fact, extremely likely that if they don't try to do this, they will again regret not doing this and regret it greatly. Thus, providers should similarly urge them to do this as opposed to their just informing them that this likely is the case. They should encourage them, for example, and even specifically suggest that they might take a lock of their baby's hair and take pictures of their child. Parents again have here reported how meaningful these mementos have turned out to be for them. Many, contrariwise, have expressed their deep and unremitting feeling of loss that they chose not to do this when they could have. ${ }^{17}$

\section{Providers' seeing and noting these babies' beauty}

We may in some instances allow ourselves to be too much limited by what we believe makes and doesn't make sense. As providers, we may do better for our patients by recognizing what may be other truths that patients or in this case parents may be much more moved to hear. ${ }^{18}$ Here, for example, this section's crowning example of this is the beauty that providers, like these parents, may find in their newborn infants even after they have died. Counter-intuitively again, perhaps, then, providers should speak of and to even babies who have died by their name, refer when speaking of and to them as babies who are "normal" and more than this, even, not hesitate to comment on these babies' beauty. ${ }^{19}$

That parents may find their own infants not only beautiful but more beautiful than any others is a reality providers should keep in mind in every context. A most important example is when a child is born who has even a severe impairment. Providers may with the best of intentions and even seeking to maximally empathize, say, after the baby is born or at a follow up appointment, that they are "sorry". The effect of their saying this may be just the opposite of what these providers intend. These parents may in response be deeply resentful.Always. They may never forget. "My baby is beautiful," such a mother may say, "as much as and in fact more beautiful than any other child." A provider may even say that such a baby is perfect, that this mother should see her or him, because this baby is beautiful and beautiful for this world..$^{18}$ As this anecdote illustrates, there is no limit to the beauty a provider may see and then, moreover, be willing to express.

\section{Research}

The need to do research on COVID in pregnant women is unequivocal. ${ }^{21}$ This group has often been excluded from participation in the past to protect the fetus. Though well-intentioned, to more and most help both these fetuses and their mothers when the latter have COVID, there is so much more that we need now to know..$^{22}$ The one question and only one I shall address is when these women should be enrolled. We might most readily assume that these mothers should be enrolled during outpatient prenatal visits when they first present with the COVID virus. Pregnant women during such an early prenatal visit have greater time to deliberate. There again, however, may be a more counterintuitive consideration that may warrant priority. Namely, those who come for earlier prenatal visits may be a different group and have different medical needs than those who come in just when it is time to deliver. Further, there may be benefits from enrolling in this research as well as possible harms. ${ }^{23}$ Both these considerations raise questions of justice. That is, enrolling research participants even when they are already in labor will result in findings that may more characterize this sub-group of pregnant women with COVID. Further, these women, too, may then benefit if there are benefits to be had. Finally, while the main argument against this is that while they are in labor, this group may be less able to deliberate and reflect, the difference between what they and women receiving prenatal care may experience may be less disparate than it otherwise would be due to COVID. That is, women coming for prenatal care with this infection may be preoccupied and distressed also, already by their knowing that they have this virus.

\section{Conclusion}

This piece explores some key practical interventions that may be particularly beneficial for pregnant women who have the COVID virus. Considerations of delivering at home, bonding, and undergoing ECMO are discussed as are interventions when these mothers' fetuses have died or will die shortly after birth. Core, possibly counterintuitive suggestions are that providers should urge these mothers and their partners to see, hold, and even bathe their babies after they have died and that providers shouldn't hesitate to tell these mothers how beautiful their babies are, again even though and after they have died. Researchers should consider allowing these mothers to enroll in their protocols even when they come in already in labor because this in several way furthers justice to them. The importance of providers considering whether to institute these measures during the one chance they may have echoes the risk faced by these parents. They will not be able to change their mind later.

Authors aware of this state this in this way: "Professionals in hospitals and in the community have only one chance to provide care that fosters the clinical, emotional, practical and psychosocial wellbeing of parents who have experienced stillbirth. By ensuring that parents receive care that is clinically skilled, emotionally intelligent, consistent and authentically caring, there is the best chance that, even in the midst of a difficult situation, they will have the healthiest experience possible, as well as the best chance of achieving optimum well-being in the longer term." ${ }^{24}$

\section{Acknowledgments}

None.

\section{Conflicts of interest}

Author declares that there is no conflict of interest.

\section{Funding}

None.

\section{References}

1. Zimmermann P, Curtis N. COVID-19 in Children, Pregnancy and Neonates: A Review of Epidemiologic and Clinical Features. Pediatr Infect Dis J. 2020;39(6):469-477. 
2. Haller M, Norman SB, Davis BC, et al. A model for treating COVID-19related guilt, shame, and moral injury. Psychol Trauma. 2020;10.1037/ tra0000742.

3. Grünebaum A, McCullough LB, Bornstein E, et al. Professionally responsible counseling about birth location during the COVID-19 pandemic. J Perinat Med. 2020;48(5):450-452.

4. Baley J, Committee on Fetus and Newborn. Skin-to-Skin Care for Term and Preterm Infants in the Neonatal ICU. Pediatrics. 2015;136(3):596599.

5. Rasmussen SA, Smulian JC, Lednicky JA, et al. Coronavirus Disease 2019 (COVID-19) and pregnancy: what obstetricians need to know. Am J Obstet Gynecol. 2020;222(5):415-426.

6. Pacheco LD, Saade GR, Hankins GDV. Extracorporeal membrane oxygenation (ECMO) during pregnancy and postpartum. Semin Perinatol. 2018;42(1):21-25.

7. Park ES, Cho IY. Shared decision-making in the pediatric field: a literature review and concept analysis. Scand J Caring Sci. 2018;32(2):478-489.

8. Meltzer EC, Ivascu NS, Stark M, et al. A Survey of Physicians' Attitudes toward Decision-Making Authority for Initiating and Withdrawing VAECMO: Results and Ethical Implications for Shared Decision Making. $J$ Clin Ethics. 2016;27(4):281-289.

9. Halpern J. Responding to the need behind the question "Doctor, if this were your child, what would you do? J Clin Ethics. 2003;14(1-2):71-78.

10. Daugirdaitè V, van den Akker O, Purewal S. Posttraumatic stress and posttraumatic stress disorder after termination of pregnancy and reproductive loss: a systematic review. J Pregnancy. 2015;2015:646345.

11. Gravensteen IK, Jacobsen EM, Sandset PM, et al. Anxiety, depression and relationship satisfaction in the pregnancy following stillbirth and after the birth of a live-born baby: a prospective study. BMC Pregnancy Childbirth 2018;18(1):41.

12. Heazell AEP, Siassakos D, Blencowe H, et al. Stillbirths: economic and psychosocial consequences. Lancet. 2016;387(10018):604-616.

13. O'Leary J, Warland J. Untold stories of infant loss: the importance of contact with the baby for bereaved parents. J Fam Nurs. 2013;1:324-347.
14. Erlandsson K, Avelin P, Saflund K, et al. Siblings' farewell to a stillborn sister or brother and parents' support to their older children: a questionnaire study from the parents' perspective. J Child Health Care. $2010 ; 14 ; 151-160$.

15. Redshaw M, Hennegan JM, Henderson J. Impact of holding the baby following stillbirth on maternal mental health and well-being: findings from a national survey. BMJ Open. 2016;6(8):e010996.

16. Lathrop A, VandeVusse L. Affirming Motherhood: Validation and Invalidation in Women's Perinatal Hospice. Narratives. BIRTH. 2011;38:256-265

17. Lovell A. Some questions of identity: Late miscarriage, Stillbirth and Perinatal Loss. Soc Sci Med. 1983;17(11):755-761.

18. Cacciatore J. The Unique Experiences of Women and Their Families After the Death of a Baby. Social Work in Health Care. 2010;49:134-148.

19. Kingdon C, O'Donnell E, Givens J, et al. The Role of Healthcare Professionals in Encouraging Parents to See and Hold Their Stillborn Baby: A Meta-Synthesis of Qualitative Studies. PLoS One. 2015;10(7):e0130059.

20. Cacciatore J, Bushfield S. Stillbirth: The Mother's Experience and Implications for Improving Care. Journal of Social Work in End-of-Life \& Palliative Care. 2007;3:59-79.

21. Buekens P, Alger J, Bréart G, et al. A call for action for COVID-19 surveillance and research during pregnancy. Lancet Glob Health. 2020;8(7):e877-e878

22. Chen L, Jiang H, Zhao Y. Pregnancy with Covid-19: Management considerations for care of severe and critically ill cases [published online ahead of print, 2020 Jul 4]. Am J Reprod Immunol. 2020;e13299.

23. Bernstein L. Study: Pregnant women can pass virus to babies. The Washington Post. 2020.

24. Downe S, Schmidt E, Kingdon C, et al. Bereaved parents' experience of stillbirth in UK hospitals: a qualitative interview study. BMJ Open. 2013;3(2):e002237. 